\title{
Are we assessing correctly our students? Spain versus Finland
}

\section{Camacho-Miñano, María del Mara ${ }^{\mathrm{a}}$ del Campo, Cristina ${ }^{\mathrm{b}}$; David Pascual-Ezama ${ }^{\mathrm{c}}$;} Urquia-Grande, Elena $^{c}$; Rivero, Carlos ${ }^{b}$; and Akpinar, Murat ${ }^{d}$

${ }^{a}$ Department of Accounting, University College of Financial Studies (CUNEF), Spain, ${ }^{b}$ Department of Statistics and OR (Decision Analysis), Universidad Complutense de Madrid, Spain, ${ }^{\mathrm{c} D e p a r t m e n t}$ of Financial Economics and Accounting II, Universidad Complutense de Madrid, Spain, ${ }^{\mathrm{d}}$ School of Business, JAMK University of Applied Sciences, Finland.

\begin{abstract}
The aim of this paper is twofold: first, to analyse the comparison of coursework and final examination between Finland and Spain to test if there are differences in assessment methodologies; second, to study whether there are different factors (such as gender, age, subject, students' motivation, and preferences) that have an impact on the assessment of students from the two countries. The final grades obtained by 117 freshmen enrolled on the Statistics and/or Financial Accounting subjects in Business Administration Degree are analyzed. The most interesting results are that the coursework mark is higher than the final examination in both subjects in both Universities, except for male students enrolled in statistics. Also variables such as gender, type of subject and students preferences have an impact on academic outcomes.
\end{abstract}

Keywords: Assessment; EHEA; coursework; final exam; active learning. 


\section{Introduction}

In the past few years, university access and participation rates have raised significantly, internationalization and life-long learning have become essential and graduates employability has become an essential concern. The European Higher Education Area (EHEA) has made Higher Education Institutions (HEI) focus on a a more dynamic teaching methodology and a student-centered learning approach, among other changes, leading to an improvement in education. The EHEA has also presented a challenge for lecturers shifting from traditional teaching to active and dynamic methodologies where the students "are doing something besides passively listening" (Ryan \& Martens 1989, p.20). However, these changes are being difficult to implement as new creative teaching methodologies require higher human resources development, more research in education, new classroom infrastructures, new quality assessment systems and smaller student-teacher ratios, finally, more investment in higher education. Taking into account all of these changes, the teaching experiences of some lecturers evidence the concern about one basic issue in the "creative" process of students' learning: the assessment of this learning. Currently universities publish subjects' syllabus or contents of the subjects adapted to active learning methodologies and schedules adapted to the European Credit Transfer System (ECTS) for all universities belonging to the EHEA to have comprehensive and homogeneous degrees. However, in most of the cases, assessment homogenization has not been achieved yet. Assessment has been defined as 'the process of evidencing and evaluating the extent to which a candidate has met or made progress in learning contents towards the assessment criteria' (Cox et al., 2008, p. 34). As Hand et al. (1996) explains "assessment is seen as a cost driver" (p. 105) due to the implication of academic staff in this time-consuming and complex process. At the same time, assessment is valued as a major influence upon the quality of the learning process (Gibbs, 1992). Therefore, nowadays, assessment is a strategic matter for completing the syllabus with the EHEA requirements. Therefore assessment should serve multiple purposes such as providing information about student learning, student progress, teaching quality, and for program and institutional accountability (Fletcher et al., 2012).

With the EHEA environment, assessment criteria has changed to a more holistic system embodying both the student's daily effort and the final examination. Therefore, following active methodologies, the final grade of a subject is the weighted mean between the coursework and the final examination marks. Formal examination refers to closed-book time-constrained written essay, test or exercises, very similar to the traditional unique format of assessment. Coursework refers to alternative assessment of different activities the student must perform including work in group essays, oral presentations, simulations, etc (see Camacho-Miñano et al., 2015). The logical hypothesis is that students with higher grades in coursework will have the highest grades in the final exams because they are studying in a continuous way, they are engaged in their learning and they have done much 
more practice, enhancing the real understanding of the subject. However, several empirical studies show the opposite results, that coursework grades are higher than the final exam (see Yorke et al., 1996; Tian, 2007).

Therefore, two universities from Spain and Finland, the Universidad Complutense de Madrid (UCM) and the Jyväskylä University of Applied Science (JAMK), respectively, have experience on cooperation among teachers of Statistics and Accounting. They have exchanged experiences on applying new teaching methodologies. Moreover, as Finland is one of the outstanding countries in European education (Grek, 2009) it could be an example to follow for other continental countries such as Spain, a country with a lower performance in the PISA reports (Calo-Blanco \& Villar, 2010).

Bearing these issues in mind, the objective of this paper is twofold: first, to analyse the comparison of coursework and final examination results in two subjects of the Business Administration Degree between Finland and Spain in order to test if there are differences; second, whether there are different factors (such as gender, age, subject, students' motivation and preferences) that have an impact on the assessment among students from the two countries.

The contributions of this paper showed there are differences between Finland and Spain, depending on the students' perception, students' gender and type of course. Moreover, this study highlights implications for managers, teachers and students in order to improve assessment criteria.

\section{Sample data and Method}

The participants were 117 freshmen enrolled on the Statistics and Financial Accounting subjects in the Business Administration undergraduate degree, taught in English in both universities. They were divided in 61 students enrolled at the Universidad Complutense de Madrid (Madrid, Spain) and 56 students at the JAMK University of Applied Science (Jyvaskyla, Finland) from which $46 \%$ of the respondents were male and $40 \%$ female.

The research variable analyzed is the final grade obtained by the already mentioned 117 freshmen enrolled on the Statistics and/or Financial Accounting subjects in the Business Administration Degree. Grades range from 0 to 10, where 0 means the worst possible result and 10 the best one. The grades are divided into two intervals: grades in $[0,5)$ mean failure and grades in $[5,10]$ mean success, improving as they approach 10 . With the EHEA methodology the final exam is not the only component of the final grade. The final exam (FE) consisting in an invigilated closed-book time-constrained examination with only a weight of $60 \%$ or $70 \%$ depending on the university (UCM or JAMK, respectively). The other part of the final grade, called coursework $(\mathrm{CW})$, is composed of active participation, assignments (exercises, cases, simulations, real-world problems, etc.) and interim class tests 
(Heywood, 2000; Camacho-Miñano et al., 2015). Also the students have two opportunities in the year to sit for the final exam and pass the subject, while the coursework component is obtained during the lecturing period.

The students were asked to fill in a questionnaire of 20 items divided in three sections: demographic data (age, gender, nationality and working status), background data (university access exam grade, degree position in university application, previous knowledge of subjects or math score) and some learning strategies (preferred ways of study, preferred type of evaluation, team working preferences).

Out of the 117 enrolled students only 111 participated in the survey where respondent rates were different depending on the question because not all of the students answered all the questions, being higher in JAMK. Missing data was not considered.

The sample is almost homogeneous because most of the questions on the survey give similar values, but there is a great difference in their working status. While the majority of students in JAMK are working (77\%) in UCM only a $33 \%$.

\section{Results and findings}

Analysing the evaluation differences between coursework assessment and final exam assessments it can be seen in the box plot (Figure 1) that for a majority of the students $(58 \%)$ the coursework mark $(\mathrm{CW})$ is bigger than the final exam mark (FE). However, the difference between coursework and final exam marks (Diff) is higher for JAMK students (mean and median more than cero) with smaller dispersion. A variance analysis confirmed that those differences on the "Diff" variable are statistically significant.

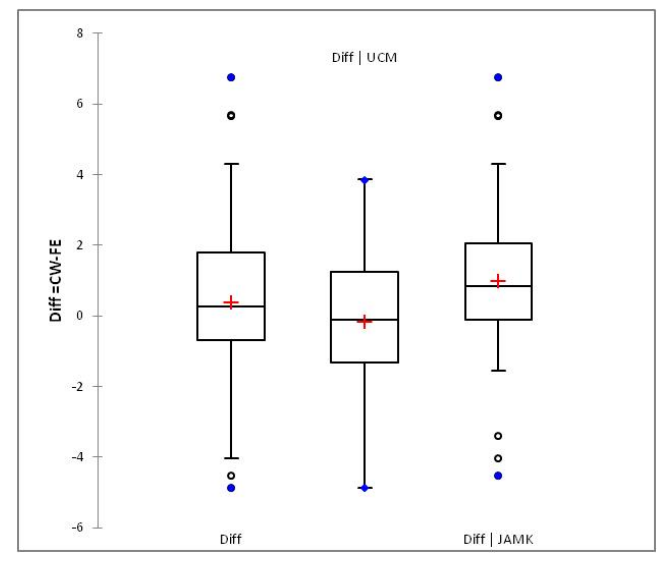

Figure 1. Diff variable box plots

As it can be observed in the Figure 1 the three distributions are quite symmetrical as the mean and the median are very similar with also the whiskers of similar length. The 
distribution for JAMK is a little right skewed, as can be seen from the length of the right whisker and from the fact that the mean is higher than the median. It can be also seen in Figure 2 that a majority of points are below the diagonal $(\mathrm{CW}=\mathrm{FE})$, meaning the coursework mark $(\mathrm{CW})$ is higher than the Final exam mark (FE). In fact, $58 \%$ of the students have higher $\mathrm{CW}$ than $\mathrm{FE}$, but percentages are quite different depending on the country: while in Spain only $47 \%$ students has higher CW than FE, in Finland the percentage increases to $74 \%$.

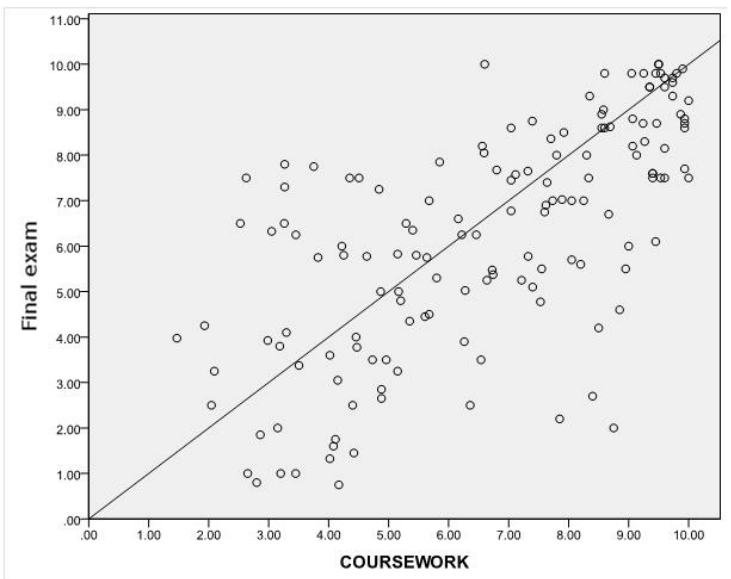

Figure 2. Coursework mark against final examination mark scatterplot

There is a great difference in the values of the difference regarding the universities, as in both the coursework and the final exam marks the values in JAMK are much higher than in UCM, as it can be seen in Figures 3.a and 3.b.

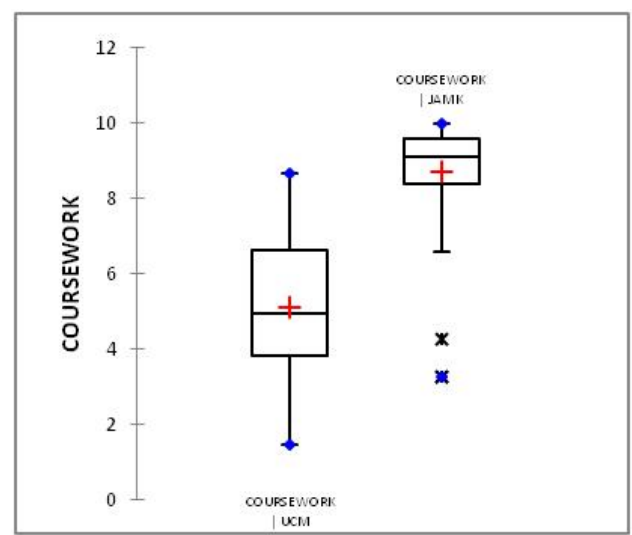

Figure 3a. Coursework box plots by university

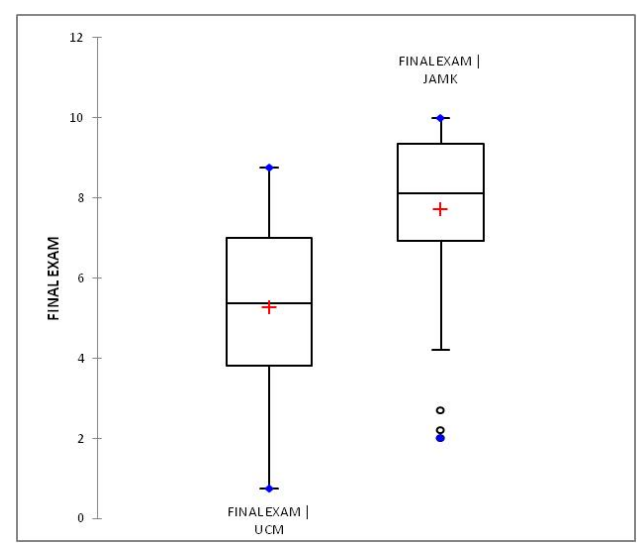

Figure 3b. Final exam box plots by university 
Regarding the subjects (Accounting and Statistics), Statistics has, in average, higher values in both the coursework and final exam than in Accounting (mean and median are higher), but the difference is similar (see Figures 4.a, 4.b).

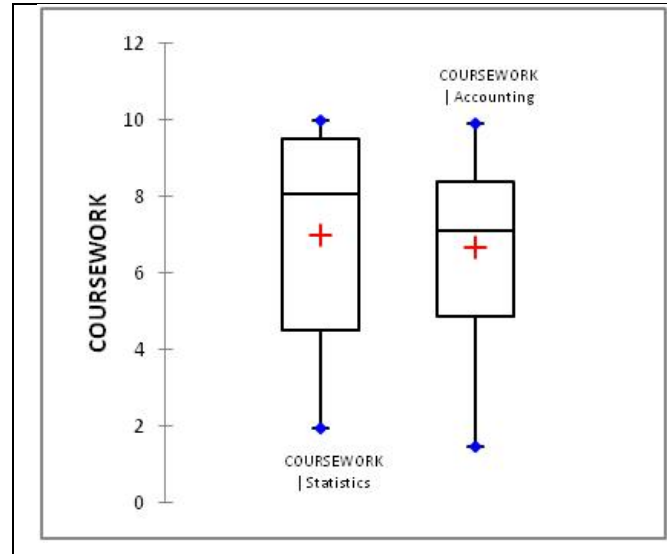

Figure 4a. Coursework box plots by subject

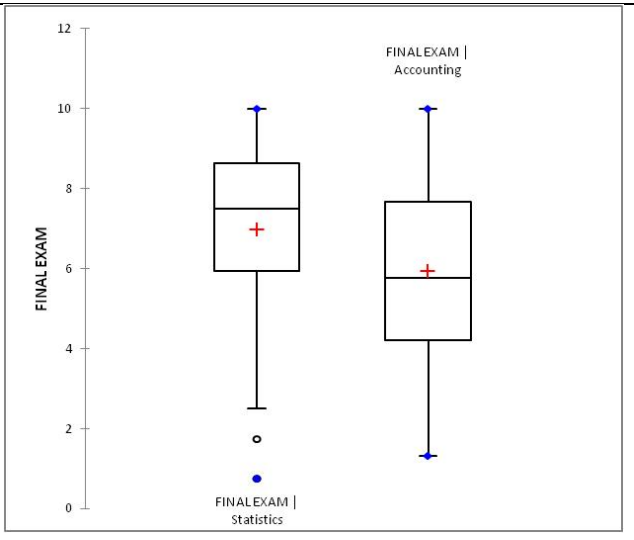

Figure 4b. Final exam box plots by subject

In order to analyse the influence of different students' factors on assessment regression and variance analyses were carried out. The coursework $(\mathrm{CW})$ and the final exams marks (FE), as well as the difference between them (Diff) were used as dependent variables whereas the other 16 variables, three quantitative and twelve qualitative factors, coming from the questionnaire (final grade, number of calls ${ }^{1}$, preferred evaluation type, University access examination, Maths grade, gender, motive for electing the degree, degree position in the university application, type of lecturer, study method, learning style and team work preferences) were used as explanatory variables. Only gender, type of subject and students' preferences had influence on the coursework and final exam differences between the analysed groups from Finland and Spain.

\section{Discussion and conclusions}

Our findings report that, in general, in both universities and for both subjects learning was enhanced by student involvement in the learning process, activities and environment that were most directly related to the learning outcomes (Struyen et al., 2008; Alauddin \& Khan, 2010), but coursework marks have resulted higher than the examination ones (Murdan, 2005). Moreover, there are some differences in gender in the same way in line with Woodfield et al. (2005) and Simonite (2003).

\footnotetext{
${ }^{1}$ Number of calls is the number of times a student has previously sat for the final exam (from cero to four times in our sample).
} 
Secondly, there are differences in Finland and Spain depending on the university's assessment culture, gender and course. Those differences may be due to cultural factors (Baeten et al., 2008). Another explanation could be that Spanish teachers are not assessing in a right way the skills and competences defined to be assessed in each coursework because of less experience in active learning methodologies and because there is still a challenge of assessing key competences across the curriculum (Pepper, 2011).

Finally, a teacher discussion on the manner of assessment should be opened between both universities in order to promote more creativity in the ways to assess learning outcomes. A proposal could be to mix the variety of evaluation methods (portfolios, quizzes, long and short exercises, problem based learning, etc.) in order to balance out non-systematic errors and avoid subjectivity. Another proposal may be to have external evaluators for the final exam.

This study has some limitations such as that the sample size is small and the analyses are focused only in two subjects and only in two countries. Thus, more studies in this line are needed to generalize the present findings. Our future research lines will be to increase the sample with more students, more subjects and more countries in order to contrast the obtained results. Moreover, it could be interesting to analyse the characteristics of students according to clusters or to test different ways of assessment.

\section{Acknowledgements}

This research was partially supported by the Spanish Ministry of Economy and Competitiveness under the R\&D project Inte-R-LICA (The Internationalisation of Higher Education in Bilingual Degrees) for the period 2014-2016 (REF. FFI2013-41235-R).

\section{References}

Alauddin, M. \& Khan, A. (2010). Does performance in progressive assessment influence the outcome in final examination? An Australian experience, Educational Assessment, Evaluation and Accountability, 22 (4), 293-305.

Baeten, M., Dochi, F. \& Struyven, K. (2008). Students' approaches to learning and assessment preferences in a portfolio-based learning environment. Instructional Science 36, 359-374.

Calo-Blanco, A. \& Villar Notario, A. (2010). Quality of education and equality of opportunity in Spain. Lessons from PISA. Working papers no. 6. Fundación BBVA. http://www.fbbva.es/TLFU/dat/dt_6 2010.pdf. Accessed 13 November 2012.

Camacho-Miñano, M.M.; Urquia-Grande, E.; Pascual-Ezama, D. \& Rivero-Menendez, M.J. (2015). Recursos multimedia para el aprendizaje de la Contabilidad Financiera en los grados bilingües. Revista Educación XXI, 19 (1), 63-89.

Cox, M.J., Schleyer, T., Johnson, L.A., Eaton, K.A. \& Reynolds, P.A. (2008). Making a mark-taking assessment to technology. British Dental Journal, 205, 33-39. 
Fletcher, R.B., Meyer, L.H., Anderson, H., Johnston, P. \& Rees, M. (2012). Faculty and Students Conceptions of Assessment in Higher Education. Higher Education, 64, 119133.

Gibbs, G. (1992). Improving the quality of student learning. (Bristol, Technical and Educational Services).

Grek, S. (2009). Governing by numbers: the PISA 'effect' in Europe. Journal of Education Policy, 24 (1), 23-37.

Hand, L., Sanderson, P. \& O’Neil, M. (1996). Fostering deep and active learning through assessment. Accounting Education, 5 (1), 103-119.

Heywood, J. (2000). Assessment in higher education. (London, Jessica Kingsley).

Murdan, S. (2005). Exploring relationships between coursework and examination marks: a study from one school of pharmacy. Pharmacy Education, 5, 97-104.

Pepper, D. (2011). Assessing key competences across the curriculum-and Europe. European Journal of Education, 46(3), 335-353.

Ryan, M.P. \& Martens, G.G. (1989). Planning a College Course : A Guidebook for the Graduate Teaching Assistant. The National Center for Research to Improve Postsecondary Teaching and Learning, Michigan. Available at http://eric.ed.gov/?id=ED314998.

Simonite, V. (2003). The impact of coursework on degree classifications and the performance of individual students. Assessment and Evaluation in Higher Education, 28 (5), 459-470.

Tian, X. (2007). Do assessment methods matter? A sensitivity test. Assessment and Evaluation in Higher Education, 32, 387-401.

Yorke, M., Cooper, A. \& Fox, W. (1996). Module mark distributions in eight subject areas and some issues they raise. In Modular higher education in the UK in Focus, ed. $\mathrm{N}$. Jackson. (105-107). London: Higher Education Quality Council.

Woodfield, R., Earl-Novell, S. \& Solomon, L. (2005). Gender and mode of assessment at university: should we assume female students are better suited to coursework and males to unseen examinations? Assessment and Evaluation in Higher Education, 30, 35-50. 